\title{
Ferramentas da Engenharia Semiótica na busca por rupturas de comunicabilidade e interação
}

Semiotic Engineering tools in the search for
communicability and interaction ruptures

Mateus de Souza Monteiro ${ }^{1}$

Soraia Silva Prietch ${ }^{2}$ 


\section{Resumo}

Diante da necessidade de um Sistema de Doação de Livros, de uso simples e eficaz, buscou-se a aplicação do Método de Inspeção Semiótica (MIS) e Método de Avaliação da Comunicabilidade (MAC), que, possibilitou a coleta de dados referente às falhas e rupturas na comunicação do sistema analisado. Além disso, utilizou-se também a Linguagem de Modelagem para Interação como Comunicação (MoLIC), como ferramenta epistêmica. Por fim, este trabalho propõe o uso do MoLIC em conjunto com o MAC como uma forma de apoio na busca por rupturas de comunicabilidades. O objetivo é analisar como os usuários reagiram aos elementos de prevenção de rupturas comunicativas projetadas pelo designer.

Palavras-chave: Engenharia Semiótica; Pesquisa com usuários; Avaliação; MOLIC; MOLIC e MAC

\section{Abstract}

In view of the need for a Book Donation System of simple and effective use, it was sought to apply the Semiotic Inspection Method (SIM) and the Communication Evaluation Method (CEM), which make it possible the data collect regarding failures and ruptures in the communication of the system analyzed in this article. In addition, the MoLIC (Modeling Language for Interaction as Conversation) as an epistemic tool. Therefore, this paper proposes the use of MoLIC with CEM, as a way of support in the search of communicability ruptures. The objective is analyse how the users react to the communicative rupture preventions elements projected by the designer.

Key-words: Semiotic Engineering; Users Research; Evaluation; MoLIC; MoLIC e MAC

ISSN: 2316-7963

${ }^{1}$ Mestrado em Ciências da Computação, UFMT (mateuskalz@gmail.com)

${ }^{2}$ Doutora em Engenharia Elétrica, UFMT (soraia.roo@gmail.com) 


\section{Introdução}

O Sistema avaliado neste trabalho, teve seu desenvolvimento iniciado durante a disciplina de Programação em Ambiente Web II, em um curso de graduação de Sistemas de Informação. Na ocasião, a disciplina não incluía o uso de conceitos de Interface Humano-Computador (IHC); nesse aspecto, o Sistema foi projetado de "dentro para fora", ou seja, concebido primeiro representações de dados, algoritmos e arquitetura do sistema (BARBOSA e SILVA, 2010). Segundo Barbosa e Silva (2010), a consequência dessa abordagem está ligada ao fato de conceber um sistema interativo inapropriado para o mundo que o cerca, devido a possibilidade da compreensão equivocada sobre como e por quem será utilizado o sistema.

A motivação de se propor esse tipo de sistema foi que, o processo atual de doação de livros da Biblioteca da Instituição de Ensino Superior (IES) ocorre de forma manual e, até certo ponto, de maneira simples. Em função disto, o manuseio do sistema deve ser claro e descomplicado a ponto de não diminuir o desinteresse do usuário com o sistema. Pois caso ocorra, o usuário pode voltar a utilizar o método manual atual. $O$ fato do processo de doação ser manual também é ruim para os clientes (gestores da Biblioteca), pois devido a quantidade de atividades a serem realizadas não é possível, atualmente, manter um registro dos dados e gerar relatórios para conhecer padrões de doações e os perfis dos doadores, ou para fornecer feedback aos doadores sobre suas doações.

Além disso, esse tipo de sistema deve levar em conta a variedade dos perfis de potenciais usuários. Assim sendo, considerou-se necessário voltar um passo atrás no ciclo de projeto, de modo que diversas lacunas fossem preenchidas com conhecimento relevante para a consolidação da aplicação. Nesse sentido, decidiu-se seguir o caminho apontado por Pressman et al. (2016), o qual afirma que quanto mais a equipe entender como os usuários interagem com o sistema, mais a equipe estará capacitada a caracterizar de maneira apropriada os requisitos e a construir modelos de análise e projetos proveitosos.

Nesse contexto, este artigo tem como principal objetivo avaliar a comunicabilidade do sistema de doação por meio de avaliações com usuários da biblioteca e doadores em potencial, bem como avaliar o sistema de doação em busca de rupturas e falhas de comunicação. Conforme o resultado dessas avaliações, validar e/ou promover melhorias no sistema, tendo como objetivos específicos:

- Identificar e analisar os problemas de comunicabilidade;

- Remover barreiras da interface que prejudicam a comunicação entre o sistema e seu(s) utilizador(es);

- Tornar o aprendizado da aplicação fácil, eficaz e eficiente;

- Analisar as prevenções de rupturas disponíveis no sistema e de que forma os usuários reagem a estes diálogos expressados pelo sistema.

Além disso, este trabalho propõe uma extensão do diagrama de interação da Linguagem de Modelagem para Interação como Comunicação (MoLIC) em conjunto com o Método de Avaliação Comunicativa (MAC), buscando analisar de que forma o usuário reage aos tratamentos de rupturas comunicativas. $O$ uso do MoLIC em conjunto com o 
MAC pode funcionar como uma forma de apoio na busca por rupturas de comunicabilidade presentes em um sistema, utilizado como objeto de avaliação do MAC. Uma vez que os métodos de observação permitem ao avaliador o registro e análise de reações reais de usuários com os elementos presentes na interface (BARBOSA e SILVA, 2010).

As seções posteriores abordam, respectivamente, abordagem sobre os métodos utilizados, os resultados da aplicação do Método de Inspeção Semiótica (MIS), do MAC, do diagrama de interação MoLIC e, por fim, as considerações finais.

\section{Abordagem sobre os métodos utilizados}

Em função do problema abordado no artigo, foram escolhidos métodos de avaliação fundamentadas na área de estudos de signos e linguagens (BARANAUSKAS e ROCHA, 2003), a Engenharia Semiótica (EngSem). Segundo Prates et al. (2006), os métodos de avaliação da EngSem proveem ferramentas para facilitar a interpretação do avaliador e para avaliar a qualidade de metacomunicação sobre as mais diversas instâncias da interação humano-computador. Além disso, conforme Barbosa e Silva (2010), seu foco de investigação é a comunicação entre designer, usuário e sistema. Os métodos de avaliação da comunicabilidade, MIS, MAC e MoLIC escolhidos para uso neste trabalho são fundamentados na EngSem.

Em relação ao MIS, esse método deve ser executado por um especialista, o qual examina uma diversidade de sinais, os quais os usuários são expostos ao interagir com artefatos computacionais (PRATES, 2006). Neste sentido, decisões sobre interação e interface com o usuário devem ser resultado de projetos cuidados sob a responsabilidade de um profissional com conhecimentos de IHC (BARBOSA E SILVA, 2010) e não apenas artefatos gerados de análise de requisitos. Na maioria dos casos, a aplicação do MIS se divide em 5 ou mais passos: a inspeção de sinais estáticos; a inspeção de sinais dinâmicos; inspeção dos sinais meta comunicacionais; a conclusão; e a construção da mensagem do designer para o usuário.

No que se refere ao MAC, Oliveira (2010) o descreve como um método de investigação, que envolve a participação de usuários em um ambiente controlado. Diferente do MIS, o MAC envolve a observação e a gravação da interação de como os usuários interagem com o sistema (MATTOS, 2010). Os métodos de observação permitem ao avaliador coletar dados sobre problemas reais que os usuários enfrentam (BARBOSA e SILVA, 2010), antecipando algumas potenciais consequências de determinadas escolhas de projeto (MATTOS, 2010).

Sobre a MoLIC (Modeling Language for Interaction as Conversation), esta foi criada com o objetivo de apoiar a reflexão sobre o artefato que está sendo projetado e o que está sendo comunicado por ele (SANGIORGI e BARBOSA, 2010). Segundo Barbosa e Gonçalves (2013), a linguagem MoLIC funciona como uma ponte entre os estágios de análise e construção da interface em si. A linguagem é usada para representar a interação humano-computador como conversa entre o designer e o usuário, contendo todos os assuntos e diálogos possíveis entre eles, mas sem apresentar detalhes de interface ou de plataforma tecnológica (SANGIORGI e BARBOSA, 2010).

A última versão da MoLIC é composta por três artefatos: o diagrama de interação, 
a lista de metas e o esquema conceitual de signos (SANGIORGI e BARBOSA, 2010). Contudo, neste trabalho, o foco foi no diagrama de interação, definido por Barbosa e Silva (2010) como a representação de qual forma os objetivos do usuário poderão ser atingidos durante a interação. Neste sentido, utilizando o diagrama de forma epistêmica, ou seja, como uma ferramenta de reflexão a metacomunicação, no auxílio de como lidar com as eventuais rupturas de comunicação. No que se refere à estrutura do diagrama de interação, esta é dividida em sete elementos: (i) ponto de abertura, (ii) ponto de encerramento, (iii) acesso ubíquo, (iv) processo do sistema, (v) fala de transição, (vi) fala de recuperação de ruptura e (vii) cena.

As rupturas comunicativas, representadas no diagrama de interação MoLIC, são falhas na comunicação entre o preposto do designer e o usuário que podem ocorrer durante a interação (BARBOSA e SILVA, 2010). Para cada ruptura identificada, o designer deve representar os tipos de apoio e prevenção à recuperação da ruptura oferecida aos usuários (BARBOSA e SILVA, 2010). Esses tipos de apoio podem ser classificados nas seguintes categorias (BARBOSA e PAULA, 2003):

Prevenção passiva: o preposto do designer tenta evitar que haja uma ruptura, fornecendo explicações sobre a linguagem de interface. Por exemplo, apresenta uma dica como "(dd/mm/aaaa)" ao lado de um campo de data. Prevenção apoiada (ou alerta) ao identificar uma situação como causa potencial de um ruptura, descreve a situação e solicita que o usuário tome uma decisão informada sobre os rumos da interação. Prevenção ativa, proposto do designer impede que o usuário emita falas inválidas que causem um ruptura. Por exemplo, habilita ou desabilita um botão de acordo com o estado atual do sistema ou impede que o usuário digite letras ou símbolos em campos numéricos.

Por fim, este trabalho propõe o uso do MoLIC em conjunto com o MAC como uma forma de apoio na busca por rupturas de comunicabilidade presentes no formulário utilizado como tarefa proposta durante as as avaliações no MAC. O objetivo é analisar como os usuários reagiram aos elementos de prevenção de rupturas comunicativas apresentadas pelo designer.

\section{Resultados da aplicação do MIS}

A aplicação do MIS, dividiu-se em dois cenários. Os quais cenários foram:

- $\quad$ Cenário do doador - A Persona Diego gostaria de disponibilizar alguns exemplares dos seus livros autorais para a biblioteca da instituição. Recentemente ficou sabendo, em conversa com outros professores, do Sistema de Doação. Em casa, utilizando o notebook, preencheu os dados dos dois livros no formulário e enviou para a biblioteca da instituição onde leciona.

- Cenário da bibliotecária - A Persona Rosana trabalha como coordenadora da biblioteca da instituição há quase três anos. Agora com o Sistema de Doação no ar, Rosana finalmente pode avaliar no computador da biblioteca os pedidos de doações dos livros antes de serem levados à biblioteca.

Uma das rupturas encontradas, é representada na Figura 1, na qual a frase "quantidade destes livros" do placeholder no formulário pode gerar uma confusão ao 
usuário do sistema, uma vez que a construção denota que possa ou tenha que haver mais de um livro para concluir o pedido de doação.

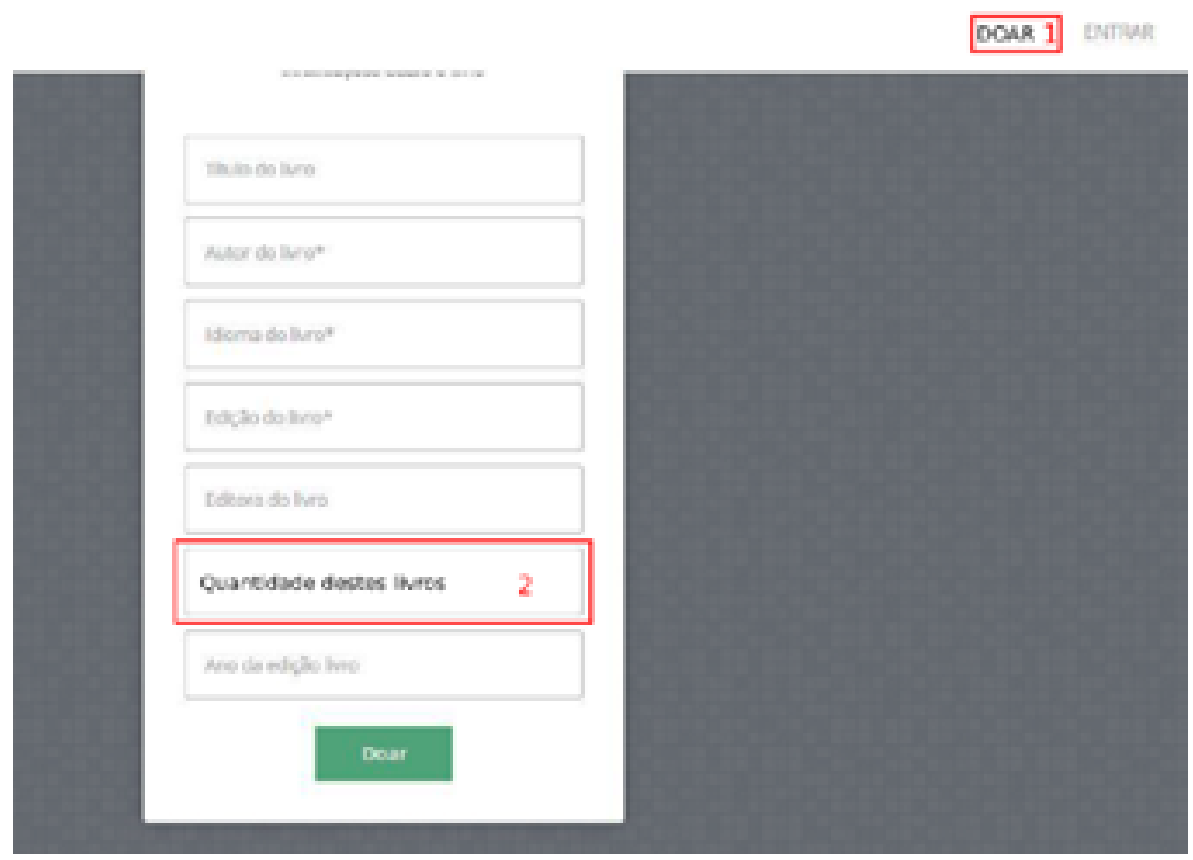

Figura 1: Formulário de doação. (Fonte própria)

No primeiro cenário, para o qual não é necessário realizar login para executar as tarefas, a busca por rupturas do sistema, encontrou falhas na barra de navegação, no formulário de doação e em alguns signos e mensagens de apoio. A partir das análises realizadas, dos signos metalinguísticos, estáticos e dinâmicos presentes na interface do Sistema de Doação, foi possível reconstruir a seguinte meta-mensagem consolidada:

- (Quem é você, usuário?) Eu acredito que você seja um usuário da internet e que deseja realizar a doação de um ou mais livros. Acredito que você prefere verificar se o(s) livro(s) que deseja doar estão aptos a compor o acervo, antes de levá-los à biblioteca.

- (O que precisa fazer?) Para poder realizar a doação, você precisa preencher um formulário contendo informações pessoais e do livro. Os campos do formulário que disponibilizei para você são: Campos Pessoais (nome, e-mail, em qual Câmpus universitário a biblioteca se localiza) e Informações sobre o livro (Título do livro, Autor do livro, Idioma do livro, Edição do livro, Editora do livro, Quantidade dos livros e o ano da Edição do livro).

- (De que maneira prefere fazê-la (fazer a doação) e por quê?) Você prefere que o formulário não possua muitos campos, pois não quer que este processo seja cansativo. Você também quer saber o resultado da avaliação do bibliotecário de uma maneira descomplicada. Por esse motivo, a resposta do pedido de doação vai para o seu e-mail, tendo em vista que está habituado com a utilização desta ferramenta.

No segundo cenário é necessário realizar o login antes de acessar a Dashboard do usuário bibliotecário. Ao acessar com as credenciais corretas, o bibliotecário entra 
no Painel de Controle do Usuário, e depara-se com uma tela que apresenta as informações sobre o pedido de doação recente.

Após a verificação realizada pelo Bibliotecário, independente da ação realizada (Aceitar ou Negar) é apresentado uma mensagem de confirmação da ação. Porém ao recusar o pedido, não é apresentado um campo que possibilite ao usuário bibliotecário colocar os motivos da recusa, tendo em vista que estes motivos podem ser específicos e, até em alguns casos, a solução pode ser resolvida com um novo envio de formulário.

Uma das principais rupturas encontradas é que, ao confirmar a ação, o processo de envio do e-mail é iniciado, e não é apresentado feedback informando que o processo está em andamento e nem quanto tempo isso pode levar. Além disso, não existe uma mensagem de confirmação quando o usuário se desconecta do sistema.

A partir das análises realizadas, dos signos metalinguísticos, estáticos e dinâmicos presentes na interface do Sistema de Doação, referente ao usuário bibliotecário, foi possível reconstruir a seguinte meta-mensagem consolidada:

- (Quem é você, usuário?) Eu acredito que você seja um usuário da internet (já que o sistema é web). Deseja melhorar a forma de como é realizada a doação de livros para a biblioteca e controlar, da melhor maneira, a qualidade dos livros que compõem, e irão compor, o acervo.

- (O que precisa fazer?) Para realizar o controle dos pedidos de doação, é preciso que você esteja atento(a) aos pedidos recentes que são disponibilizados na página inicial da dashboard. Conforme os dados enviados no formulário e as políticas de doação da biblioteca, você deverá se orientar pelos critérios pré-definidos para aceitar ou recusar aquele pedido.

- (De que maneira prefere fazê-lo e por quê?) Você não quer que este processo seja tão trabalhoso como é atualmente, por isso disponibilizei as informações da maneira mais visível para você analisar cada pedido por vez. Como sei que às vezes você pode clicar, de forma não intencional, no botão "Confirmar" ou "Negar", coloquei uma mensagem de confirmação para você ter certeza se é realmente a sua intenção. Coloquei uma mensagem padrão para aceitar ou negar o pedido de doação, tendo em vista que o processo de análise dos pedidos é cansativo para você. Ao realizar o logoff sei que essa possivelmente é sua real intenção.

A partir da aplicação do MIS, considerando ambos os cenários descritos anteriormente, pôde-se constatar que o designer do sistema demonstrou uma certa preocupação ao confirmar a intenção do usuário em Aceitar/Negar. Contudo, existe a falta alguns signos estáticos e dinâmicos que possibilite a acessibilidade. Dentre os pontos negativos levantados, destacam-se:

- A falta de explicação em relação ao elemento "Entrar" na barra de navegação no topo da página, pois não é necessário entrar para realizar o pedido de doação e o login é restrito aos bibliotecários;

- A falta de textos de aviso explicativos e de auxílio ao usuário sobre como preencher o formulário de forma correta;

- A falta da informação sobre a política de doação da Biblioteca do Câmpus, 
tendo em vista que a política de doação é um critério crucial em relação a avaliação do pedido;

- A falta de um feedback visual quando o usuário bibliotecário confirmar a avaliação do pedido de doação;

- A falta de acessibilidade;

\section{Resultados da aplicação do MAC}

Por se tratar de um sistema em que o perfil dos usuários é bem diverso, não foi necessário a aplicação de um questionário de seleção dos participantes. Contudo, foi dada a preferência aos participantes que estivessem habituados ao cotidiano da Universidade. Foram utilizados dois questionários durante as avaliações. O questionário de perfil envolvia perguntas como: Sexo, Idade, Nível de escolaridade, Curso (se aplicável), Conhecimento com informática, tempo de uso, tempo gasto e frequência na internet, e também sobre doação de livros. Em relação ao questionário realizado ao final das avaliações, Tabela 1, era pedido que assinalasse, com um " $X$ ", as respostas de 1 a 5 de acordo com opinião do participante, sendo 1 a nota mais baixa (não/nunca, péssima, negativa) e 5 a nota mais elevada (concordo fortemente, sim/sempre, excelente, positiva); e NA = Não se aplica.

\begin{tabular}{|c|c|c|c|c|c|}
\hline Questiondirio de avaliaçăo & 1 & 2 & 3 & 4 & 5 \\
\hline Como voce classifica a ajuda disponibilizada pelo sostema? & & & & & \\
\hline $\begin{array}{l}\text { Considera que o numero de cliques (em lirks ou itens de menu) para alingir o } \\
\text { objetivo final (de realzaçlo da tarefa) sâ minimos? }\end{array}$ & & & & & \\
\hline Como classifica a tacildade de uso do sistema? & & & & & \\
\hline Como classifica a clareza dos termos/oútulos/efquatasicones? & & & & & \\
\hline Como classifica a organizaphlo das informaples na interface? & & & & & \\
\hline Como classifica a estetica da inerface? & & & & & \\
\hline Vocb recomendara esse sistema sos seus amigos? & & & & & \\
\hline Vocb acessaria o sistema a partir de agora caso necessario? & & & & & \\
\hline Woch considera que o resultado é apresertado em formato útil? & & & & & \\
\hline Voct concluin com sucesso o seu cbjetivo de realizacalo de pedido de doacha?? & & & & & \\
\hline
\end{tabular}

Tabela 1: Questionário de avaliação (Fonte própria)

Ambos foram criados e realizados pelo Google Forms, o qual possibilita a criação de formulários a partir do Google Drive ou de qualquer planilha já existente e registrar as respostas a este formulário. A captura das reações dos participantes e a interação do usuário com o sistema foram capturadas com o software ScreenCastify durante as avaliações do sistema.

O convite aos participantes foi feito pessoalmente no dia da aplicação das avaliações piloto. O número total de participantes na fase piloto foi de 5 pessoas. Para orientar a execução das avaliações (piloto e efetiva), criou-se um roteiro. Como primeiro passo do roteiro, foi convidar os participantes para a participação da avaliação. Caso o participante aceitasse, convidá-lo ao laboratório de informática ou pesquisa 
onde foi realizado a avaliação. Posteriormente, explicar o termo de consentimento de participação voluntária na avaliação. O termo de consentimento descrevia a pesquisa e seus objetivos principais, além das diretrizes éticas para sua realização. Depois de terem lido o termo, cada participante teve a liberdade de decidir se continuaria ou não participando do teste. Prosseguindo para a aplicação do questionário de perfil, a realização da avaliação e o questionário de avaliação. Para o usuário, foi solicitada somente uma tarefa em ambas as avaliações (piloto e efetiva), a qual era: "Realizar dois pedidos de doação no sistema, de forma que os dados do livro fossem diferentes para cada pedido".

Para o usuário, foi passado somente uma tarefa em ambas as avaliações (piloto e efetiva), a qual era: Realizar dois pedidos de doação no sistema, de forma que os dados do livro fossem diferentes de cada pedido.

\subsection{Avaliação Piloto}

$\mathrm{Na}$ avaliação piloto, procurou-se observar se os participantes entendiam corretamente o material apresentado, se o tempo de execução estava dentro do previsto e se precisava ser realizado algum ajuste no questionário e/ou na forma de atuação do mediador, de modo que a avaliação efetiva, realizada posteriormente, pudesse transcorrer como desejado. Durante a avaliação piloto, notou-se algumas falhas no processo de avaliação que poderiam atrapalhar durante a marcação das TAGS, realizada posteriormente a fase de análise dos resultados. Uma das falhas é que, no momento de realizar a doação fictícia de um livro pelo sistema, os usuários tiveram dificuldades para lembrar dados de livro ou gerar algum dado, inventado naquele momento, durante a realização da tarefa (preenchimento dos formulários no sistema).

\subsection{Avaliação Efetiva}

Após a realização do teste piloto e levantados os pontos que necessitavam de mudanças, estes foram considerados e aplicados. Entretanto, por mais que o livro facilitasse ao doador que não precisasse gerar ou lembrar das informações, os usuários gastaram quase o mesmo tempo para procurar as informações (edição, ano da edição, editora, dentre outras) nos livros. A diferença no tempo médio de execução da tarefa entre a efetiva e o piloto foi de apenas 0,10 segundos.

O critério de seleção do perfil dos participantes da avaliação efetiva, seguiu o mesmo princípio da aplicada no piloto. Assim como também o convite fora feito pessoalmente na IES. O número total de participantes foi 13. Dentre os motivos principais dos usuários que realizaram as doações para a biblioteca, estavam: "Desocupar espaço" e "Desfazer de materiais pessoais". Sendo a experiência da doação classificada pelos participantes como "Positiva" e "Indiferente".

No geral, as avaliações ocorreram sem problemas técnicos, salvo quando ocorreram quedas na conexão do laboratório onde foram realizadas as entrevistas. É interessante notar que, a proporção de usuários que tiveram dificuldades para concluir ou não realizarem a tarefa é alta em relação aos que conseguiram concluir sem pro- 
blemas. A diferença é de até $30 \%$ e, novamente, parte desta taxa está diretamente relacionada às rupturas de comunicação que o sistema possuía. Porém, no questionário de avaliação respondido pelos participantes, 92,3\% afirma que concluiu sem nenhuma dificuldade o pedido de doação.

\subsection{Sugestão dos participantes}

As sugestões nas avaliações (piloto e efetiva) feitas pelos participantes, foram:

- Incremento do campo: estado dos livros (conservação, rasuras, páginas faltando, dentre outros), volume, condição;

- Retorno da tela para o campo com o erro;

- Ao finalizar o pedido, não retornar para a tela do formulário;

- Incluir opções de respostas abertas, visto que alguns livros não possuem edição, editora, ano, dentre outras;

- Feedback na conclusão do pedido de doação;

- Possibilitar o cadastro para doadores, uma vez que a doação possa ocorrer com uma certa frequência;

- Possuir um campo de ajuda sobre como preencher os campos dos formulários.

É relevante ressaltar que dentre as sugestões realizadas pelos participantes das avaliações, apenas a mensagem de sucesso no envio do pedido de doação e as seções iniciais se assemelham aos pontos levantados no MIS.

\subsection{Etiquetagem}

Na etapa de Etiquetagem, após a captura das interações durante as avaliações, a execução é analisada por um especialista e associadas as expressões feitas pelos usuários etiquetadas ao tipo de ruptura de comunicação entre o usuário e o sistema identificado (MATTOS, 2010). Na Tabela 2, são apresentados os tipos e as quantidades de rupturas verificadas durante a avaliação efetiva e a avaliação piloto. As marcações: Não obrigado; e Socorro; não apresentaram nenhuma marcação tanto na avaliação Efetiva quanto na Piloto e, por esse motivo, não são apresentadas na tabela.

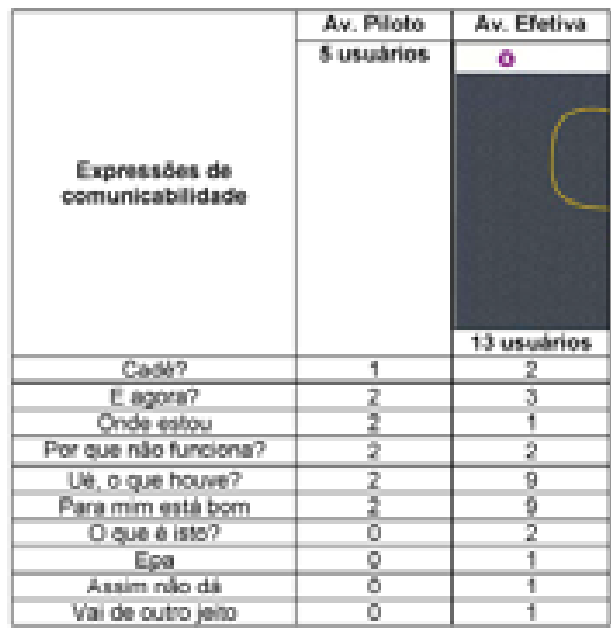

Tabela 2: Etiquetagem das avaliações piloto e efetiva.(Fonte própria) 
A Figura 2, apresenta um dos usuários da avaliação efetiva perdido após obter um resultado inesperado do sistema ao executar uma ação. Isso pode ser identificado pela forma que o usuário reage ao resultado da ação e ao deslizar, movimenta o cursor na tela sem um objetivo definido, sendo representado pelo traço amarelo na imagem.

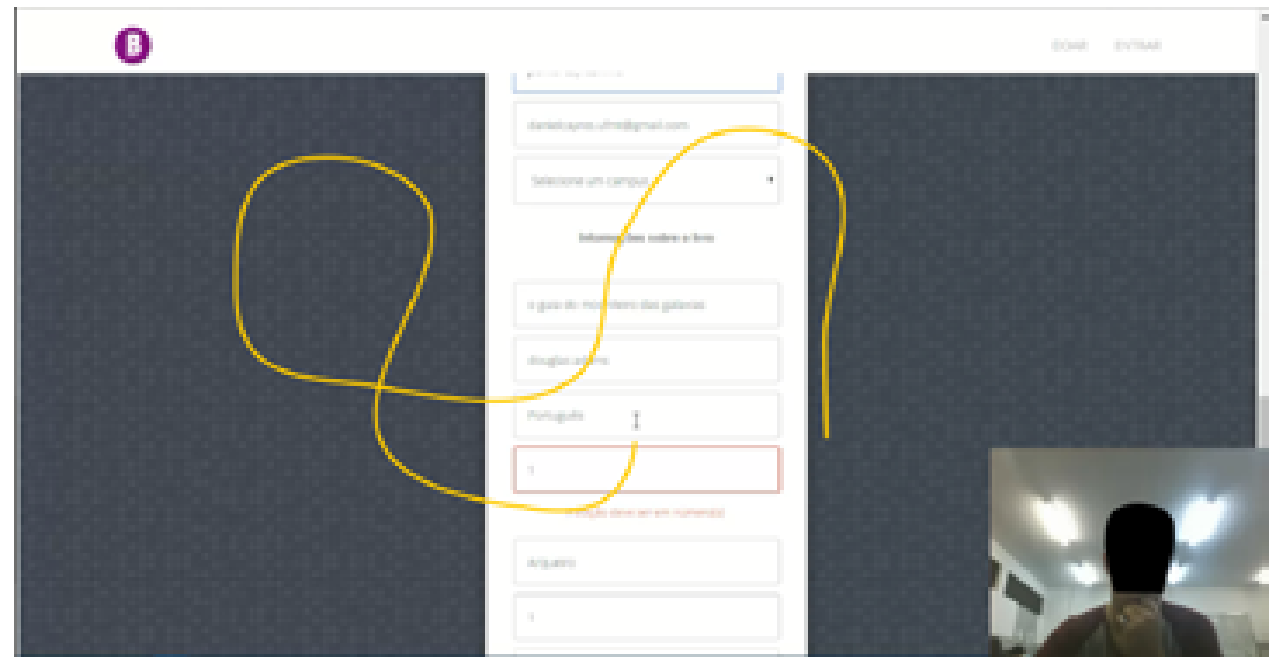

Figura 2: Participante da avaliação apresentando um padrão da tag "Ué, o que houve?". (Fonte própria)

O traço amarelo, representado na Figura 2, foi desenhado sobre a captura de tela, representando o movimento do cursor de forma manual (usando a ferramenta $\mathrm{XY}$ ) sem o auxílio de ferramenta de rastreamento do olhar ou do mouse (eye-tracking ou mouse-tracking).

\subsection{Perfil Semiótico}

Neste ponto, após a aplicação das avaliações, é gerado um perfil semiótico que consiste em um diagnóstico aprofundado do processo de metacomunicação entre projetista e usuário (MATTOS, 2010). Realizado como se o projetista dissesse ao usuário através do sistema:

Caro usuário, o sistema de doação de livros é uma ferramenta que eu criei para você, que precisa realizar doações para bibliotecas. O sistema de doações, além de permitir o envio do pedido de doação, também tem a função de ajudá-lo na compreensão da composição do acervo da biblioteca. É recomendado que você confira os dados antes do envio do formulário, pois mesmo que possua um controle dos dados, em algum caso pode passar algo despercebido e não apresento nenhuma mensagem para confirmar a execução do pedido. Eu também recomendo que no envio errado do formulário, não clique no botão doar no topo da página, pois isso atualiza a página e perde os dados anteriores do formulário.

Após realizar as interpretações posteriores ao MIS e o MAC, foi possível levantar os seguintes pontos: melhorias de comunicabilidade; melhorias na base de dados; melhorias na interface; melhorias na funcionalidade do sistema e melhorias na organização dos elementos na interface do sistema. 
Contudo, devido à grande quantidade de sugestões e melhorias identificadas, fez-se necessário, a princípio, a seleção de algumas melhorias para implementação inicial, as quais foram:

- Colocar aviso aos usuários doadores sobre a não necessidade de realizar login para envio do formulário de doação;

- Adicionar botão para aumentar e outro botão para diminuir o tamanho da fonte do formulário;

- Alterar placeholder dos campos dos formulários com exemplos de preenchimento dos campos;

- Adicionar campos: estado de conservação do livro (conservação, rasuras, páginas faltando, dentre outros) e volume;

- Nos campos volume e edição, deixar claro para os usuários que eles devem preencher somente números;

- Alterar cores das páginas adicionando mais contraste;

- Melhorar as seções informativas sobre: a doação e composição do acervo;

- Após o envio do formulário, apresentar ao usuário quais foram as informações inseridas no formulário e então confirmar o pedido;

- Alterar mensagem de sucesso;

- Notificar a existência de erro e melhorar as mensagens de tratamento do formulário.

\section{Aplicação MoLIC}

Apesar da linguagem MoLIC ser como uma ponte entre os estágios de análise e construção da interface em si (SANGIORGI e BARBOSA, 2010), neste trabalho, o diagrama de interação do MoLIC, apresentado na Figura 3, foi aplicado com a interface já criada e após o desenvolvimento do sistema. Como dito na seção de embasamento teórico, o objetivo da aplicação é compreender as decisões feitas pelo designer e como está organizado o fluxo de interação do sistema.

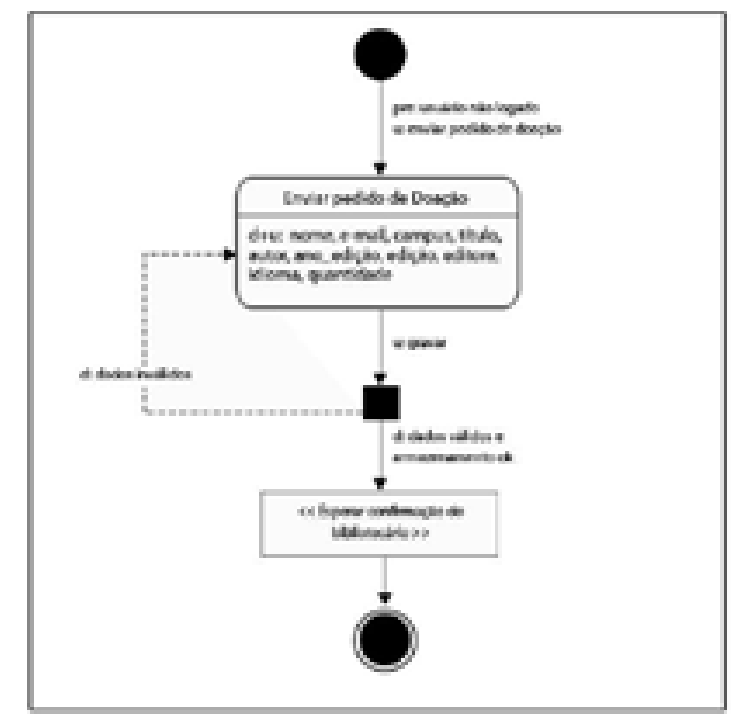

Figura 3: Diagrama de Interação Enviar pedido de Doação. (Fonte própria) 
O processo de interação com o formulário de doação tem a pré-condição do usuário não estar logado. Assim como comentado na aplicação do MIS, na seção 3, o sistema não apresenta nenhum tipo de Prevenção Apoiada ou Prevenção Passiva para informar o usuário de que ele não precisa e nem pode estar logado para realização do pedido. Outro ponto é o excesso de regra sem prévia conversa com bibliotecário, uma vez que, durante a aplicação das avaliações do MAC, alguns dos participantes são bibliotecários e comentaram a respeito do que era ou não era obrigatório, quando pedido feito de forma manual.

Os tratamentos utilizados como prevenção de dados inválidos na cena de Enviar pedido de doação, estão apresentados na Tabela 3. Os dados estão distribuídos baseado no modelo de representação de mecanismos de prevenção de Barbosa e Silva (2010).

\begin{tabular}{|c|c|c|}
\hline \multicolumn{3}{|c|}{ Rupturas comunicativas - Cena Enviar pedido de doaçato } \\
\hline Campo & Provençào & Recuperaçào \\
\hline Nome do(a) doador(a) & $\begin{array}{l}\text { Prevenç১o ativa: campo obrigatório e } \\
\text { caracteres minimos (5) }\end{array}$ & $\cdot$ \\
\hline $\begin{array}{l}\text { Campus para onde sera } \\
\text { doado a obra }\end{array}$ & Prevençâso ativa: campo obrigatónio & $\cdot$ \\
\hline E-mail do(a) doador(a) & $\begin{array}{l}\text { Prevençầ ativa: campo obrigatónio e invalidez } \\
\text { de campo. }\end{array}$ & $\cdot$ \\
\hline Ano de publicaço da obra & $\begin{array}{l}\text { Prevençlo ativa: campo obrigatóno e invalidez } \\
\text { de campo. }\end{array}$ & . \\
\hline Titulo da obra & $\begin{array}{l}\text { Prevençâo ativa: campo obrigatório e } \\
\text { caracteres minimos (3) }\end{array}$ & - \\
\hline Autor obra & $\begin{array}{c}\text { Prevença ativa: campo obrigatónio e } \\
\text { caracteres minimos (3) }\end{array}$ & . \\
\hline Editora obra & $\begin{array}{c}\text { Prevençlo ativa: campo obrigatório e } \\
\text { caracteres minimos (3) }\end{array}$ & $=$ \\
\hline Quantidade de cbra(s) & $\begin{array}{l}\text { Prevençao ativa: campo obrigatcrio e apenas } \\
\text { numenco }\end{array}$ & - \\
\hline Ediçâo obra & $\begin{array}{c}\text { Prevençào ativa: campo obrigatcino e apenas } \\
\text { numerico }\end{array}$ & - \\
\hline
\end{tabular}

Tabela 3: Rupturas comunicativas da Cena Enviar pedido de doação. Fonte: Adaptado de Barbosa e Silva (2010).

Como pode ser visto na Tabela 3, não somente a falta de recuperação com prevenção passiva, recuperação apoiada ou controle de erros atinge a não necessidade do usuário logar no site para realizar o pedido, mas como também o formulário de doação. Barbosa e Silva (2010) afirmam que o designer deve ajudar o usuário a re- 
cuperar de um erro, informando-lhe sobre o que ocorreu, as consequências disso e como reverter os erros indesejados.

\subsection{Proposta o Diagrama de Interação em conjunto com o MAC (DoMAC)}

Apesar de existir diversas fontes de informações que ajudam o designer a conhecer a forma como o usuário interage com o produto, tais como: feedback dos usuários, arquivos de log, análise competitiva e pesquisa em geral (COURAGE e BAXTER, 2005), optou-se pelo uso do MoLIC junto com o MAC. A escolha deste método foi devido a sua característica de riqueza de dados provenientes de interações reais dos usuários, permitindo identificar problemas que os participantes enfrentam em cenário real de uso. Estudar estes fenômenos de interação entre seres humanos e sistemas computacionais permitem compreendê-los, melhorando a concepção, construção de produtos tecnológicos aliados, chegando até ao aumento de sua produtividade e bem-estar (BARBOSA e SILVA, 2010).

Contudo, agrupar grande volumes de dados da aplicação de dois métodos, MoLIC e MAC, é sem dúvida um grande desafio, ainda mais quando aplicada a um cenário de uma equipe com profissionais de diferentes formações. Em função disto, uma alternativa de representação destes dados em uma forma compacta e de linguagem única é o diagrama de interação. O Diagrama de Interação em conjunto com o MAC (DoMAC), apresentado na Figura 4, possui um conjunto de novos elementos que permitem a representação dos dados das avaliações. Além disso, tem como objetivo ser mais do que uma ferramenta epistêmica, mas ser um aliado do designer na tomada de decisões.

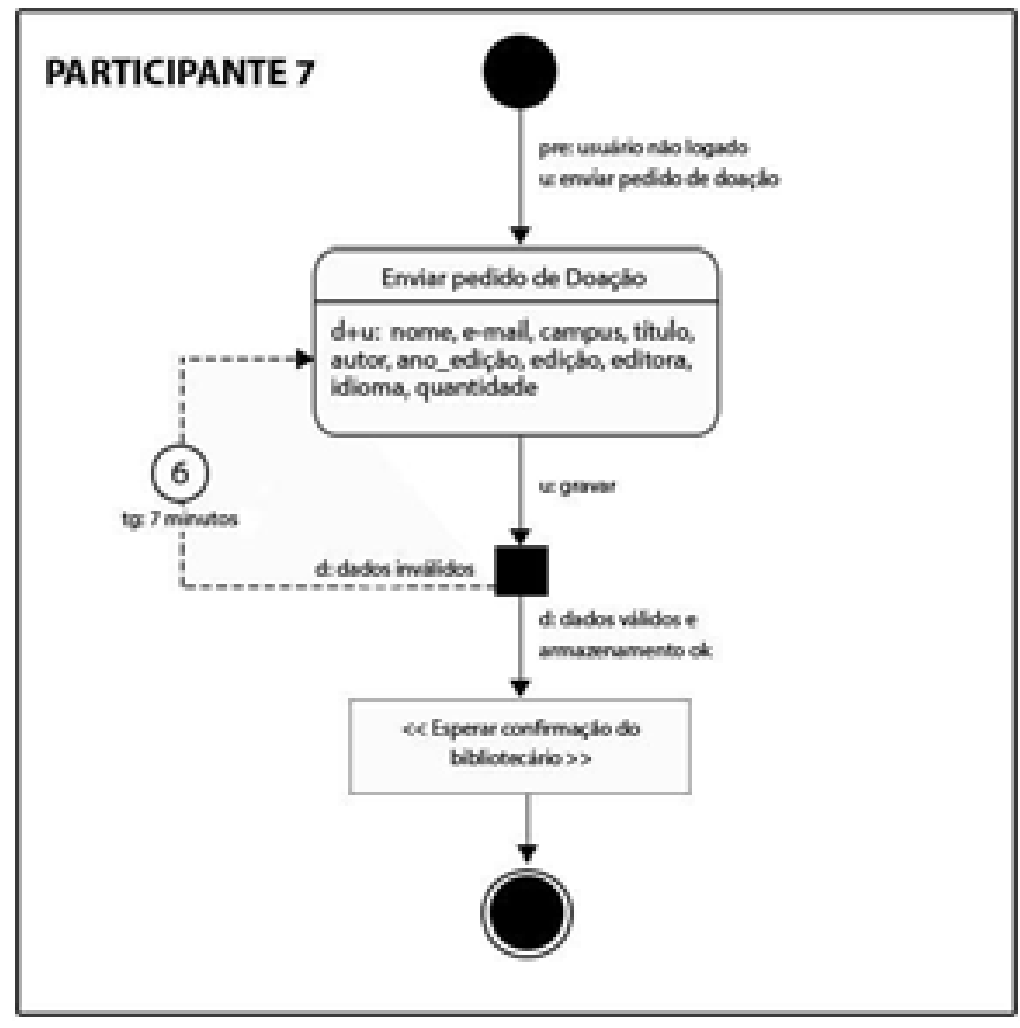

Figura 4: Aplicação DoMAC (Fonte própria 
À Figura 3, em comparação ao Diagrama de Interação, da Figura 4, foram acrescentados alguns elementos de informações das avaliações do MAC. O círculo com borda, representa a quantidade de vezes que o usuário levou para concluir o processo daquela cena e o tg, que representa o tempo gasto em execução daquele processo. O DoMAC também permite analisar os dados da média, mediana e modal dos participantes, do que concluiu com mais facilidade e o que demorou mais tempo na conclusão.

O Participante 7, usuário que levou mais tempo para concluir a tarefa proposta, utilizou 7 minutos para completar o processo da cena "Envio do pedido de Doação", como demonstra a Figura 4. Em consideração a média dos usuários da avaliação efetiva, que foi 4, o que levou ao usuário a utilizar 3 minutos a mais que a média e 6 tentativas para concluir a tarefa? Poderia ser um problema de comunicabilidade? Ou até mesmo um problema na forma como o tratamento auxilia o usuário a concluir o processo? Assim como dito anteriormente na aplicação do MIS, também pela listagem dos tratamentos de prevenção do sistema e confirmado pela gravação da avaliação, é possível notar que o usuário teve problemas com dois campos: edição e ano. Observando mais atentamente, nem o campo e nem a Prevenção Ativa apresentam exemplos de como o usuário deve preencher os campos, levando-o a frustração e quase a desistir da avaliação.

O desenvolvimento de um projeto para o designer, tem como meta o bem-estar do usuário (HARADA e SCHOR, 2016). Além disso, ao interagir com o sistema, os usuários interpretam as mensagens construídas pelos designers e respondem a elas (BARBOSA e GONÇALVES, 2013). Portanto, para que a prevenção e o tratamento das rupturas comunicativas sejam eficientes, é necessário que a mensagem alcance o maior número de pessoas, pois do contrário, a reação dos usuários pode não ser a projetada pelo designer.

\section{Considerações Finais}

Os objetivos propostos para este trabalho foram atingidos. A aplicação dos métodos de avaliação da EngSem gerou uma série de registros de rupturas e falhas na comunicação do sistema, sejam elas identificadas por especialista ou por participantes das avaliações, devido ao seu nível de detalhamento na coleta dos dados e aos protocolos para a condução da investigação.

Dentre os métodos utilizados para aplicação neste trabalho, o MAC destacou-se pela quantidade de sugestões levantadas pelos participantes, durante a avaliação, e durante a fase de etiquetagem e interpretação das gravações. Contudo, a fase de preparação do MAC, demanda mais estudo e preparo que a aplicação do MIS, que por sua vez não necessita de participação de terceiros, nem depende de algum local específico para ser realizado.

Em relação à aplicação do MoLIC, este demonstrou ser de grande importância, uma vez que, possibilitou uma visão detalhada acerca dos recursos de interação entre o designer e o usuário. A proposta deste trabalho serviu como aliada na hora de validar e optar pelas melhorias levantadas pelos métodos MIS e MAC, pois ao analisar 
atentamente as gravações das avaliações, foi possível notar que cada usuário possui suas características e, que estas características, influenciam sua participação e a forma como interage com sistemas interativos (BARBOSA e SILVA, 2010).

Além disso, a quantidade de requisitos gerados para a fase de melhoramento do sistema foi maior do que esperava-se, demandando uma filtragem e seleção dos requisitos (funcionais e não funcionais) que necessitavam mais urgência para serem atendidos. Os critérios de seleção partiram da onde mais os usuários tiveram dificuldades na execução das tarefas.

Por fim, a perspectiva é de continuidade do trabalho, sendo o próximo passo previsto: a realização do MAC e DoMAC sob o ponto de vista da(o) bibliotecária(o). Posteriormente, as melhorias e, por fim, o encaminhamento de relatório técnico com solicitação de implantação do sistema na biblioteca da IES.

\section{REFERÊNCIAS}

BARBOSA, Simone Diniz Junqueira; PAULA, Maíra Greco de. Designing and Evaluating Interaction as Conversation: a Modeling Language based on Semiotic Engineering. In: A. JORGE, Joaquim; JARDIM NUNES, Nuno; FALCÃO E CUNHA, João (eds) Interactive Systems. Design, Specification and Verification. Portugal: Funchal, 2003, p. 16-33.

BARBOSA, Simone Diniz Junqueira; GONÇALVES, Gustavo. Uso da MoLIC WOz como ferramenta de apoio a avaliação formativa baseada no diagrama de interação MoLIC. In: VII Simpósio sobre Fatores Humanos em Sistemas Computacionais, IHC 2013. Anais do XII do Simpósio brasileiro de Fatores Humanos em Sistemas Computacionais, 2013. Manaus, p.228-237.

BARBOSA, Simone Diniz Junqueira; SILVA, Bruno Santana da. Interação Humano-Computador. Rio de Janeiro: Elsevier, 2010.

COURAGE, Catherine; BAXTER. Kathy. Understanding your users: a practical guide to user requirements, methods, tools, and techniques. San Francisco: Morgan Kaufmann Publishers, 2005.

HARADA, Fernanda Jordani Barbosa; SCHOR, Paulo. Design centrado no humano para compreensão de problemas em pacientes idosos com deficiência visual. HFD Human Factors in Design, Florianópolis, v.5, n.9, p. 18-37, 2016.

MATTOS, Bernardo Augusto Maciel. Uma extensão do método de avaliação de comunicabilidade para sistemas colaborativos. Minas Gerais, 2010. Dissertação (Mestrado) - Ciência da Computação, Universidade Federal de Minas Gerais. 
OLIVEIRA, Erica Rodrigues de. Investigação sobre a aplicabilidade dos métodos de avaliação da comunicabilidade ao domínio educacional. Minas Gerais, 2010. Dissertação (Mestrado) - Ciência da Computação, Universidade Federal de Minas Gerais.

SOUZA, Clarisse Sieckenius de; LEITÃO, Carla Faria; PRATES, Raquel Oliveira; SILVA, Elton José da. The semiotic inspection method. In: VII Simpósio sobre Fatores Humanos em Sistemas Computacionais, IHC 2006. Anais do VII Simpósio sobre Fatores Humanos em Sistema Computacionais. Natal, p. 148-157.

PRESSMAN, Roger; MAXIM, Bruno. Engenharia de Software: uma abordagem profissional. Porto Alegre: AMGH Editora Ltda, 2016.

ROCHA, Heloísa Vieira da; BARANAUSKAS, Maria Cecília Calani. Design e Avaliação de Interfaces Humano-Computador. Campinas: NIED/Unicamp, 2003.

SANGIORGI, Ugo Braga; BARBOSA, Simone Diniz Junqueira. Estendendo a linguagem MoLIC para o projeto conjunto de interação e interface. In: X Simpósio sobre Fatores Humanos em Sistemas Computacionais, IHC 2010. Anais do IX Simpósio sobre Fatores Humanos em Sistemas Computacionais, 2010. Minas Gerais, p. 61-70. 